\title{
Morir para vivir. La muerte celular como proceso regulador ${ }^{\&}$
}

\author{
(Dying to live. Cell death as a regulatory process)
}

\author{
María Belén Campero*1, Cristián Favre ${ }^{2}$, Cristian Saborido 3 \\ ${ }^{1}$ Centro de Investigaciones Filosóficas, Buenos Aires, Argentina \\ ${ }^{2}$ Instituto de Fisiología Experimental, CONICET, UNR, Rosario, Argentina \\ ${ }^{3}$ Departamento de Lógica, Historia y Filosofía de la Ciencia, UNED, Madrid, España
}

\begin{abstract}
RESUMEN: Habitualmente, la organización de los sistemas vivientes se explica apelando a una finalidad intrínseca que se fundamenta en la supervivencia biológica. Pero, paradigmáticamente, es inevitable observar que el destino final de todos los organismos vivos es la muerte. En este trabajo defenderemos que, desde un enfoque organizacional, hay una forma de muerte-la Muerte Celular Regulada-que, lejos de ser mera «ausencia de vida», es un proceso de regulación biológica característico del auto-mantenimiento biológico de los multicelulares.
\end{abstract}

PALABRAS CLAVE: muerte, organización, regulación, mecanismo, vida.

ABSTRACT: Usually, the organization of living systems is explained by appealing to an intrinsic purpose that is based on the biological survival. However, paradigmatically, it is inevitable to observe that the final destiny of all living organisms is death. In this work, we defend that, from an organizational approach, there is a form of death-Regulated Cell Death-that, far from being a mere «absence of life», is a process of biological regulation and a feature of self-maintenance in multicellular organisms.

KEYWORDS: death, organization, regulation, mechanism, life.

\& El orden de los autores sigue un criterio alfabético. Todos ellos han contribuido igualmente en la elaboración de este trabajo. Este artículo se ha realizado en el marco del proyecto de investigación «MECABIOSOC. Mecanismos en las ciencias: de lo biológico a lo social (FFI2017-89639-P)». Los autores quieren agradecer además sus comentarios a versiones previas de este trabajo a Emilio Cáceres, Javier González de Prado y dos revisores anónimos de Theoria.

* Correspondencia a/Correspondence to: María Belén Campero. Centro de Investigaciones Filosóficas, Buenos Aires, Argentina. Miñones 2073. C1428ATE Buenos Aires. Argentina - bcampero@gmail.com - http://orcid.org/0000-0001-8867-9836

Cómo citar/How to cite: Campero, María Belén; Favre, Cristián; Saborido, Cristian (2020). «Morir para vivir. La muerte celular como proceso reguladorn; Theoria. An International Journal for Theory, History and Foundations of Science, 35(2), 197-215. (https://doi.org/10.1387/ theoria.20514).

Recibido/Received: 11 enero, 2019; Versión final/Final version: 09 agosto, 2019.

ISSN 0495-4548 - elSSN 2171-679X / (C) 2020 UPV/EHU 


\section{Introducción}

El debate sobre la definición de vida es uno de los más tradicionales y fecundos de la biología teórica y la filosofía de la biología contemporáneas. Son muchas las diferentes propuestas que se han lanzado al mercado filosófico que intentan delimitar las características que distinguen a los seres vivos del resto de la materia natural (véase, por ejemplo, la compilación de Bedau y Cleland (2010)). Esta relevancia de la vida en la biología difícilmente puede calificarse de sorprendente. El mismo término «biología» refiere a una «ciencia de la vida». Esta posición central de la noción de vida, no obstante, supone haber dejado a su necesario reverso, la muerte, en una posición de mero acompañante inevitable e incómodo. En filosofía de la biología parece darse por asumido que el reto importante es dar con una buena definición de vida y que la muerte se define, simplemente, por contraposición a esta. Así, los teóricos no suelen hablar de la muerte como una cuestión independiente y, cuando lo hacen, se limitan únicamente a considerarla como el contrario de la noción de vida. Basta decir que la muerte es la no-vida o, como mucho, que lo muerto es algo que en algún momento ha estado vivo y ha perdido esta condición. El interés por la muerte como fenómeno biológico tampoco era fundamental en la biología general hasta el desarrollo de la biología celular en la que, precisamente, existe un área en donde la muerte es un tema central y supone un fenómeno cuyo estudio se considera imprescindible para comprender la estructura y el funcionamiento de las células que forman parte de organismos multicelulares.

Desde mediados del siglo XIX, los biólogos perciben la peculiaridad que entrañan los procesos de muerte celular (MC). Ya Walter Flemming, en 1885, había descripto en detalle sus observaciones de una tendencia celular autodestructiva que ahora conocemos con el nombre de apoptosis (Clarke and Clarke, 1996). Sin embargo, recién en los años 60 del siglo xx con los nuevos avances tecnológicos, principalmente el microscopio electrónico y las técnicas mejoradas en histología, se pudo empezar a estudiar el fenómeno de la «muerte celular programada», como le llamaron Lockshin y Williams (1964) para diferenciarlo de los procesos de «muerte celular accidental». Otros teóricos, como el biólogo del desarrollo John W. Saunders, pusieron en el centro de la biología celular el estudio de estos procesos, constatando que «abundantes muertes, a menudo cataclísmicas, son parte del desarrollo temprano en muchos animales y es el método usual para eliminar órganos y tejidos que son útiles sólo durante la vida embrionaria o larvaria o que no son más que vestigios filogenéticos» (Saunders 1966, 154). Según afirmó Saunders, existe un «reloj de muerte» intrínseco a las células que permite al investigador predecir cuándo y de qué manera estas van a morir. A partir de aquí se comenzó a aceptar que la MC, igual que la diferenciación o el crecimiento de un órgano o un tejido, estaba «programada» en los genes de los organismos (Lockshin, 2016). Fueron Kerr, Wyllie y Currie quienes iniciaron la investigación de los diferentes mecanismos implícitos en este «impulso suicida de las células» (Kerr et al., 1972).

En la actualidad, las diferentes formas de MC son analizadas detalladamente por los biólogos celulares. Estos estudios han demostrado ser un fértil campo de estudio con repercusiones en la biomedicina: muchas terapias y tratamientos génicos se basan en lo que conocemos acerca de los procesos de muerte celular regulada, logrando grandes avances para prevenir y paliar diversas patologías, como el cáncer o las enfermedades neurodegenerativas (Galluzzi et al., 2018). 
En filosofía de la biología, no obstante, la MC ha recibido un interés prácticamente marginal. ${ }^{1}$ En este trabajo partiremos del conocimiento biológico contemporáneo de los mecanismos de MC para mostrar sus potenciales implicaciones teóricas para la filosofía de la biología. En particular, entendemos que, lejos de considerarse como una mera «ausencia de vida celular», la noción de MC engloba diferentes procesos, algunos de los cuales pueden ser vistos como regulaciones biológicas desde el enfoque organizacional. En este trabajo proponemos complementar la noción de regulación desarrollada recientemente por autores del enfoque organizacional para contribuir al entendimiento de la noción de muerte celular.

\section{II. ¿Qué es la muerte celular regulada?}

La MC se define esencialmente como la pérdida de la integridad de la membrana celular (Kroemer et al., 2005), pero ése no es sino el punto final en el que pueden converger distintos procesos que ocurren dentro de una célula y que muestran notables diferencias entre sí. De hecho, la biología celular ha dado lugar a una gran acumulación de hallazgos que llevan continuamente a cambios en la clasificación de tipos y subtipos de MC. Es frecuente que se den superposiciones en estas categorías y hay una gran controversia en torno a si es conveniente, o siquiera posible, la unificación de los criterios para esta clasificación (Galluzzi et al., 2018; Hotchkiss et al., 2009). En el fondo de esto parece hallarse una falta de consenso respecto a cómo caracterizar la MC. En este trabajo intentaremos mostrar cuáles son las características distintivas de los mecanismos de MC y por qué esta puede entenderse en algunos casos como «regulada». Argumentaremos que la muerte celular regulada (MCR) constituye un proceso biológico complejo ligado a las funciones celulares, entendidas estas, desde una perspectiva organizacional, como contribuciones al auto-mantenimiento de una organización biológica. En concreto, sostenemos que la contribución al auto-mantenimiento organizacional de la MCR se justifica por su papel regulador en la organización de una entidad multicelular.

Como un primer acercamiento, podemos decir que la MC puede darse de dos maneras distintas. Por un lado, la muerte celular accidental, aquella que se produce a causa de alteraciones físico-químicas que afectan a la célula: altas presiones, temperaturas extremas, exposición excesiva a fuerzas osmóticas, fuertes variaciones del $\mathrm{pH}$, etc. Por otro lado, la muerte celular regulada (MCR), que es el resultado de un mecanismo molecular concreto. Este tipo de muerte es un proceso biológico cuyo origen se localiza en ciertas partes componentes de la célula. En la práctica biológica, además, estos pueden ser manipulados (es decir, provocados, evitados, retrasados o acelerados) mediante intervenciones farmacológicas o genéticas (Galluzzi et al., 2016, 2018). ${ }^{2}$

Aunque constantemente se establecen nuevas pruebas bioquímicas o microscópicas para precisar tipos o etapas de una determinada forma de MCR es posible decir que esta

1 Empieza a haber notables excepciones a esto, como los recientes trabajos de Ionnidis y Psillos (2017) y Durand y Ramsey (2018).

2 Aunque queda fuera del foco de este trabajo, se ha identificado también otro tipo de muerte celular. La senescencia celular consistiría en la pérdida irreversible del potencial proliferativo asociado a características morfológicas y bioquímicas específicas de la célula. Actualmente, la senescencia celular no se considera una forma de MCR, sino un subtipo de muerte celular accidental (Galluzzi et al., 2018). 
puede ocurrir en dos casos distintos. Por un lado, puede tener su origen en perturbaciones ambientales intracelulares o extracelulares, cuando dichas perturbaciones son demasiado intensas o prolongadas para que las respuestas adaptativas puedan hacer frente al estrés y restaurar la homeostasis celular. Por otro lado, la MCR puede ocurrir en ausencia de cualquier perturbación ambiental y funcionar como un efector incorporado de programas fisiológicos para el desarrollo o la renovación de tejidos (Fuchs et al., 2011). Esta MCR se conoce en la biología celular como muerte celular programada (MCP), haciendo una acepción propia de la noción de «programa».

Si bien no nos ocuparemos aquí de examinar en detalle todas las clases de MCR que los biólogos han identificado, cabe decir que hay una convención bien extendida (Green y Llambi, 2015) en considerar que toda MCR ocurre como una consecuencia de eventos característicos que dan lugar a procesos celulares en los que participan «cascadas»o «vías de señales» específicas. Existen tres formas más frecuentes: la apoptosis, la autofagia y la necrosis. La primera involucra la aparición de «ampollas» (blebs) en la membrana celular, la condensación y fragmentación de la cromatina nuclear y el achicamiento de la célula; la segunda se caracteriza por la autofagocitosis en vacuolas específicas de los componentes de la célula, y aun de sus organelas, como la mitocondria; y la tercera se define por el hinchamiento de la mitocondria y de la célula en su totalidad y por la ruptura (precoz) de la membrana celular, sin condensación del núcleo (Green y Llambi, 2015). ${ }^{3}$ Así, podemos decir que toda MCR resulta de la activación de uno o más módulos de transducción de señales. ${ }^{4}$

Como ya dijimos, recién en los años 60 del pasado siglo xx, la MC se comenzó a concebir como un proceso activo y no como el final pasivo e inevitable de la vida de la célula.

3 La necrosis ha sido definida a veces como la pérdida de la vida celular, pero en los últimos años hay evidencia de los sucesos singulares que caracterizan a ésta como un tipo de muerte programada (Golstein y Kroemer, 2007). La necrosis es consecuentemente entendida también, al igual que la apoptosis y la autofagia, como una forma de muerte que puede sobrevenir accidentalmente por daño de la membrana y que es también una consecuencia de un programa celular específico, o, dicho de otra manera, una maquinaria o mecanismo regulado.

4 En este sentido, la MCR presupone la presencia de un mecanismo biológico en el sentido mínimo en que lo discuten, para el caso concreto de la apoptosis, Ioannidis y Psillos (2017). Ioannidis y Psillos aluden al caso concreto de la apoptosis para defender una postura a la que denominan «mecanicismo metodológico». Los autores de este trabajo defienden que la muerte celular es un fenómeno biológico que es normalmente interpretado por los biólogos como un mecanismo de las células, entendiendo la idea de mecanismo en un sentido mínimo, como un «una trayectoria causal descrita en el lenguaje de la teoría». Según Ioannidis y Psillos, la mejor forma de explicar la muerte celular consiste en adoptar una estrategia metafísicamente neutra, es decir, que se limite a describir la forma en la que los biólogos hablan de mecanismos (Ioannidis y Psillos, 2017). En su opinión, esto no tiene porqué implicar que para hablar de muerte celular se deba asumir ni explicar en detalle las características distintivas de estos procesos, sino que basta con identificar una relación causal que pueda ser descrita siguiendo el lenguaje que adopte la ciencia biológica. Tal y como demuestran Ioannidis y Psillos, la muerte celular puede abordarse científicamente adoptando un enfoque meramente metodológico como el que ellos proponen. Esto probablemente responde al reto que parece implicar la MCR para la filosofía de la biología, especialmente para los enfoques teleológicos. Sin embargo, en este trabajo adoptamos un planteamiento distinto e intentamos mostrar que es posible también dar cuenta de la MCR desde un marco teleológico concreto: el enfoque organizacional. 
A la fecha, se han revelado muchísimos aspectos bioquímicos y moleculares que explican la MCR en general y la apoptosis en particular (Fuchs y Steller, 2015). Sin embargo, no es completamente claro el rol de la MCR en los distintos organismos, en situaciones fisiológicas no patológicas, ni se ha iluminado del todo cuál es su impacto en las enfermedades. Probablemente una razón por la que ocurre esto es que la MCR parece formar parte de procesos muy diversos.

Por ejemplo, se observa necrosis dependiente de calpaína asociada a la homeostasis del pH celular en neuronas del gusano Caenorhabditis elegans (Artal-Sanz et al., 2006), apoptosis durante el envejecimiento de la levadura Saccharomyces cerevisiae (Herker et al., 2004), en el desarrollo de la mosca Drosophila melanogaster (Grether et al., 1995) y en la homeostasis de la respuesta inmune en linfocitos T humanos (Janssen et al., 2005). Más aun, en algunas situaciones y según el contexto celular, la MCR puede estimular la proliferación (Nishina et al., 2012), o la muerte (Pérez-Garijo et al., 2013) de otras células vecinas. Además, la relación entre distintos tipos de MCR no es inequívoca ni unidireccional, de manera que, así como hay situaciones en las que pueden superponerse, las hay en las que una puede ser causa o freno de otra. Por ejemplo, la inhibición de la autofagia puede aumentar la apoptosis (Maiuri et al., 2007); o la inhibición de la apoptosis puede inducir necrosis (Chautan et al., 1999).

No obstante, y más allá de la variedad con la que se ponen en juego estos tres tipos de MCR, queremos aquí encontrar aspectos comunes, a saber: 1) Se encuentran en organismos evolutivamente distantes (desde las levaduras-y aun formas rudimentarias de MCP en las bacterias-a los mamíferos) y con estilos de vida distintos. 2) Involucran vías de regulación más o menos complejas en las que participan: a. receptores de membrana y/o proteínas quinasas, b. proteínas mitocondriales y/o otras señales mitocondriales; y c. proteasas específicas (como caspasas, calpaína, catepsina, etc.). 3) La MCR es un proceso que se da por una serie de eventos, tanto de origen exógeno como endógeno a la organización celular, que constituyen una vía de señalización que, al ejecutarse, acaba con la vida de la célula, y, en esa cascada de señalización, la relación con el metabolismo energético (y, más precisamente, con la bioenergética mitocondrial) ocupa un lugar central. ${ }^{5}$

\section{La muerte celular regulada como reto para el enfoque organizacional}

La MCR resulta un reto para la filosofía de la biología porque parece contradecir una intuición muy afianzada en nuestra forma de entender los seres vivos. Es habitual asumir que los

5 Es preciso aclarar que, si bien sería interesante su desarrollo, en este estudio no nos ocuparemos de hacer un análisis detallado de la muerte celular desde la perspectiva evolutiva. Quizás la forma de MCR más estudiada desde un enfoque evolutivo sea la primera de estas tres formas, la apoptosis, que según los especialistas se conserva evolutivamente desde los eucariotas inferiores como la levadura Saccharomyces cerevisiae donde se expresa una única caspasa y donde es clara su participación en procesos diversos como el envejecimiento o la respuesta a distintos tipos de estrés (ver revisiones en Büttner et al., 2006 y Carmona-Gutierrez, 2010). No obstante, también se propone una forma rudimentaria de apoptosis en los procariotas (Rice \& Bayles, 2003; Engelberg-Kulka, 2006). Lo que conocemos como vía mitocondrial de la apoptosis puede entenderse que se remonta a la existencia de esta organela como tal, lo cual es confirmado en la apoptosis observada en las levaduras. 
sistemas vivientes operan, mediante su organización, en la tarea de permanecer en la vida. De hecho, es muy frecuente definir a los seres vivos como sistemas auto-mantenidos o autónomos (Maturana y Varela, 1980; Moreno y Mossio, 2015). Aun cuando consideremos que solo de forma metafórica es posible hablar de algo así como un conatus spinoziano en los seres vivos, la noción de organización biológica comprendida como si estuviera dirigida a un fin está en la base de gran parte de la filosofía de la biología actual. Este enfoque se fundamenta en la asunción de que hay ciertas finalidades que son inherentes al ser vivo, tales como la supervivencia o la reproducción. Consecuentemente, se trata de una perspectiva claramente teleológica, en donde la «direccionalidad hacía un fin» se utiliza como principio explicativo de los procesos y fenómenos biológicos.

Considerar que el mundo natural ha sido diseñado para ajustarse a un propósito consciente está en la base de las más antiguas reflexiones sobre el mundo que nos rodea y es una presuposición fundamental de gran parte del pensamiento más primitivo y espontáneo acerca de la naturaleza. Esta concepción es constitutiva de la cosmología de algunos pensadores que van desde Platón a los actuales defensores del Creacionismo, como los impulsores de la teoría del Diseño Inteligente. Es también uno de los pilares maestros del pensamiento teológico pasado y presente y, basta un rápido vistazo a las diferentes explicaciones sobre el orden y funcionamiento de la naturaleza de carácter religioso, para identificar una tendencia a buscar propósitos que den cuenta del diseño del mundo. Se ha defendido incluso que la forma en la que comenzamos de niños a interpretar la naturaleza, tanto orgánica como inorgánica, es precisamente teleológica (Kelemen, 2004). Parece por tanto que nuestros fundamentos intelectuales y psicológicos más básicos nos han dado una predisposición a tratar de comprender lo que nos rodea aludiendo a un telos, una intención última que explica por qué el mundo es como es (Saborido, 2014b, p. 285).

En la filosofía de la biología actual se han desarrollado diferentes marcos teóricos que muestran este tipo de perspectiva desde enfoques naturalistas, apelando a nociones aparentemente finalistas-notablemente la noción de «función»-que, sin embargo, intentan fundamentar sin apelar a intencionalidades conscientes externas. En este trabajo nos vamos a centrar en uno de estos marcos teóricos: el enfoque organizacional. ${ }^{6}$

El enfoque organizacional de las funciones biológicas (Mossio et al., 2009; Saborido et al., 2011) asume que una función biológica es un efecto producido por una parte o rasgo que contribuye al auto-mantenimiento de la organización que conforma. Los sistemas biológicos se caracterizan por originar un tipo muy concreto de organización, a la que se denomina «cierre organizacional», esto es, la acción constrictiva entre diferentes efectos de entidades que componen el sistema y que posibilitan que el ser vivo pueda seguir existiendo (Moreno y Mossio, 2015).

6 En este trabajo nos vamos a enfocar en el marco teórico organizacional porque consideramos que es el enfoque teleológico que, junto con el etiológico-evolutivo, está más desarrollado dentro del debate actual sobre las funciones biológicas (Saborido, 2014b). Además, es especialmente útil para los propósitos de este trabajo porque dentro de este enfoque se ha desarrollado un análisis teórico no solo de la noción de función sino también de la de regulación (la cual va a ser central para nuestros propósitos). Además de esto, es muy interesante abordar la muerte celular desde este enfoque porque, al contrario de otros enfoques teleológicos como el etiológico-evolutivo, el marco organizacional se centra en las propiedades sistémicas de las organizaciones biológicas, por lo que un proceso que parece tener como función la desaparición de estas organizaciones (es decir, la muerte) supone un reto evidente. 
El cierre organizacional es la realización de una red de interrelaciones entre estructuras materiales (constricciones) que ejercen una influencia sobre sus condiciones de entorno de forma tal que se posibilita que el conjunto de la red se auto-mantenga. En un cierre organizacional, cada proceso o parte que contribuye al auto-mantenimiento está dinámicamente presupuesto por el resto de partes y procesos, de tal forma que el conjunto de un sistema debe actuar de una determinada manera pues, de lo contrario, dejaría de existir (Mossio, 2013; Montevil y Mossio, 2015; Moreno y Mossio, 2015).

Esta idea de cierre organizacional permite naturalizar la noción de función y es algo que no se da en todos los sistemas auto-mantenidos. Para que haya cierre organizacional debe darse una diferenciación interna entre las contribuciones al mantenimiento del sistema. Dado que podemos identificar a ciertas partes como constricciones que ejercen efectos causales distintos que son mutuamente dependientes y que, a través del mantenimiento del conjunto, contribuyen a su propio mantenimiento, se pueden atribuir funciones a estas partes y esta atribución de funciones tiene una relevancia explicativa capaz de fundamentar tanto la teleología como la normatividad de los enunciados funcionales. Así, un rasgo tiene una función si y solo si cumple con estas tres condiciones:

C1. T contribuye al mantenimiento de la organización $\mathrm{O}$ de $S$;

C2. $\mathrm{T}$ es producido y mantenido bajo ciertas constricciones ejercidas por $\mathrm{O}$

C3. S realiza cierre organizacional (Saborido et al., 2011).

Desde este enfoque, podemos decir que el corazón tiene la función de bombear sangre porque (C1) bombear sangre contribuye al mantenimiento del organismo permitiendo a la sangre circular, lo cual posibilita, entre otras cosas, el transporte de nutrientes a las células, la estabilización de la temperatura y el $\mathrm{pH}$, etc. Al mismo tiempo, (C2) el corazón es producido y mantenido bajo ciertas constricciones ejercidas por el organismo, cuya integridad es asimismo un requisito para la existencia del propio corazón. Por último, el organismo presenta una organización que realiza cierre organizacional, pues está constituido por un conjunto de estructuras interdependientes que contribuyen al auto-mantenimiento biológico del conjunto del sistema.

Adoptando una perspectiva de raíces aristotélicas y kantianas, este enfoque afirma que la particular organización de los seres vivos nos lleva a interpretarlos como si estuvieran dirigidos a un fin. La organización de los sistemas vivos, tal como Hans Jonas (2001) propuso, se caracteriza por la inseparabilidad entre lo que son-su «ser $\gg-$ y lo que hacen - su «hacer»- Esto es distinguible, por ejemplo, en su metabolismo, a través del cual, como señalan Moreno y Mossio (2015), los seres vivos se auto-producen, se auto-reparan, y mantienen a sí mismos de forma continua. Así, la perspectiva organizacional reivindica el papel central desempeñado por la noción de organización dentro de un paradigma que coloca el énfasis explicativo en las ideas de autonomía y capacidad de auto-mantenimiento (Moreno y Mossio, 2015).

En vistas de ello, están necesariamente presentes en el análisis organizacional dos dimensiones de la autonomía biológica, conceptualmente distintas pero relacionadas entre sí. Una es la dimensión constitutiva, que supone tanto el origen del ser como su desarrollo, o sea las formas a través de la cuales este ser se hace individuo y determina en gran medida la identidad del sistema, y la otra la interactiva que es la que representa la relación del viviente con otros seres (Etxeberria y Moreno, 2007) y se ocupa de las interacciones funcionales inherentes que los organismos deben mantener con el medio ambiente (Moreno 2008). Am- 
bos aspectos son indispensables para comprender la autonomía de un organismo (Umerez, 2001) y concebirlo en un mundo sin el cual perecería (Campero y Favre, 2012). En este sentido, un ser viviente es autónomo y dependiente a la vez, y en la conformación que se establece a partir de la relación que existe entre sí mismo y el medio encuentra la capacidad de reconocer su propio fin. En otras palabras, podemos elaborar una idea más amplia de que un organismo es, entonces, una red de procesos, de relaciones que lo producen, a sí mismo, continuamente (Varela, 1979; Varela y Maturana, 1980) pero necesita, más allá de un cierre causal de autoproducción (Moreno y Mossio, 2004, 2015), producir un cierre de limitaciones que le permitan interactuar con un medio inestable (Juarrero, 2015) y que produce cambios a los que debe enfrentarse para garantizar su supervivencia.

Así pues, la perspectiva organizacional supone también un enfoque normativo de los seres biológicos. Un rasgo o componente de un sistema tiene la norma de cumplir su función porque de lo contrario el organismo está abocado a dejar de auto-mantenerse. De este modo, la muerte se presenta simplemente como un fracaso del comportamiento funcional de un ser vivo. De hecho, cuando los teóricos organizacionales han abordado la cuestión de la distinción teórica entre salud y enfermedad definieron lo patológico (es decir, lo disfuncional) como el incumplimiento del funcionamiento biológico. La enfermedad y la muerte no serían sino el resultado de un desajuste organizacional para mantener el cierre organizacional (Saborido y Moreno, 2015; Saborido et al., 2016).

No obstante, veremos en la siguiente sección que la MCR no es simplemente el resultado de un «fallo» orgánico, sino un proceso (o, mejor dicho, un conjunto de tipos muy diversos de procesos) que responde a una disposición estructural y funcional de los organismos. Defenderemos que la mejor forma de abordar la MCR, desde un enfoque organizacional, consiste en comprenderla en el marco de la organización autónoma propia de los organismos multicelulares (Arnellos y Moreno, 2015) y, más concretamente, como procesos de regulación biológica en estos (Bich et al., 2016). Es decir, sostenemos que la MCR es, además de un fenómeno celular «regulado», un proceso multicelular regulatorio.

\section{Muerte celular regulada y organización multicelular}

Los organismos deben auto-mantenerse no sólo en condiciones estables sino también, y principalmente, en condiciones potencialmente peligrosas en las que debe hacer frente a perturbaciones. En tales circunstancias, las capacidades regulatorias actúan sobre la estabilidad constitutiva y provocan situaciones de transición a partir de las cuales se modifican las condiciones de la organización para contrarrestar las perturbaciones (Moreno y Mossio, 2015). A través de mecanismos adaptativos de regulación, los organismos son capaces de asumir el control y restablecer los parámetros de uso de la energía para limitar las afecciones de las posibles variaciones que el medio pueda generar, tanto interna como externamente (Montévil y Mossio, 2015; Moreno y Mossio, 2015). Bich et al. (2016) definen la regulación como la capacidad de los organismos biológicos de reaccionar a una perturbación modificando su comportamiento interno por medio de un subsistema especializado que modula la acción de diversos mecanismos de control y elige entre varios regímenes dinámicos disponibles y viables.

Es a través de la actividad regulatoria como los organismos son capaces de establecer nuevas organizaciones. En un organismo podemos encontrar dos formas de organización 
diferenciables entre sí: una de estabilidad constitutiva y la otra de regulación. La primera se vincula con las nociones de cohesión y robustez estructural (Kitano, 2007) y puede definirse como la tendencia del organismo a conservar su estado de organización inicial. La segunda, por su parte, depende de que un conjunto de limitaciones opere cuando el cierre constitutivo está siendo interrumpido o amenazado por una perturbación (Moreno y Mossio, 2015).

Así pues, la regulación puede entenderse como el mecanismo de control ejercido por un organismo, en ciertas circunstancias, a fin de mantener sus condiciones metabólico-constitutivas y de supervivencia. La regulación permite que un sistema pueda cambiar en relación con las características del entorno (Bich et al., 2016).

Aunque la regulación biológica esté presente a nivel unicelular, como puede observarse en los procesos de quimiotaxis de las células procariotas, esta tiene una especial relevancia para los organismos pluricelulares porque es un requisito necesario para la coordinación e integración de las diferentes partes que lo componen y para que se produzca una unidad biológica, tanto desde el punto de vista constitutivo como interactivo (Arnellos y Moreno, 2015).

Un sistema pluricelular es «una entidad integrada funcionalmente debido a que su organización dinámica desempeña un papel causal en la generación de las estructuras funcionales que realmente hacen posible el desencadenamiento y la regulación del desarrollo de esa organización» (Arnellos et al., 2014, p. 878). En un pluricelular, los subsistemas celulares se mantienen como tales en tanto forman parte de unidades más amplias que engloban varios sistemas celulares integrados. La organización de todos los organismos multicelulares está sujeta a mecanismos de comunicación e interacción intercelular.

A diferencia de los organismos unicelulares, los pluricelulares generan procesos metabólicos y reproductivos acoplados (Arnellos et al., 2014), esto es, la regulación en organismos multicelulares depende de las características metabólicas incluidas en sus células individuales. Para ello es fundamental que exista una organización coordinada, que se ensamble funcionalmente y que implemente diferentes mecanismos de regulación que actúen armoniosamente con los procesos y mecanismos característicos de cada una de las células que lo conforman.

Es posible por tanto diferenciar al menos dos niveles diferentes de organización en los organismos pluricelulares: el nivel de los organismos unicelulares que lo componen y el nivel multicelular al cual la integración de cada célula da lugar. Esto conlleva la caracterización de la autonomía multicelular como una autonomía de «segundo orden» (Bich et al., 2016). La producción de los mecanismos de control reguladores que guían el desarrollo de las relaciones funcionales entre las partes unicelulares autónomas de un organismo multicelular convierten todo el sistema en una organización integrada auto-reproducible y auto-mantenible y autónoma en sí, pero en un diferente nivel jerárquico (Arnellos et al., 2014). Así pues, la regulación es requisito para la organización de los sistemas pluricelulares. Es desde este punto de vista como proponemos abordar la funcionalidad biológica atribuible a la MCR.

\section{IV.1. Caso 1: La muerte Como Regulación frente a perturbaciones EXTERNAS}

El metabolismo energético no sólo condiciona, sino que participa en la regulación de la supervivencia celular. En efecto, Green y colaboradores (2014) proponen un escenario-y 
una interesante conceptualización-en el que la apoptosis o la necrosis pueden ser iniciadas por «señales» provenientes de «perturbaciones» del metabolismo que son monitoreadas por «sensores» especializados (fundamentalmente quinasas y otras proteínas específicas) que se integran en la red de «efectores» de la maquinaria de muerte de la célula. De manera que tanto metabolitos como enzimas involucradas en circuitos metabólicos participan en el destino celular, e inversamente muchas proteínas reguladoras de la muerte tienen también funciones metabólicas, con lo cual el metabolismo y la señalización de la MC están entrelazados (Green et al., 2014).

Teniendo en cuenta este entrecruzamiento nos centraremos en el ejemplo de la MCR provocada por restricción de nutrientes. Este análisis se llevará adelante desde el enfoque organizacional que sostiene que hay diseños de organización que proporcionan las bases para identificar las condiciones en las que los componentes de un sistema actúan. Desde esta perspectiva, como mencionamos en la sección anterior, los rasgos de un sistema son funcionales si cumplen con las condiciones necesarias para el auto-mantenimiento y si sus efectos causales son contributivos al mantenimiento de toda la organización. Ahora bien, sabemos además que frente a los efectos de una perturbación-como ser en este caso la restricción nutricional-todo organismo precisa de la regulación para mantener su identidad (Bich et al., 2016). Veremos entonces, a través de los ejemplos propuestos, si la MCR puede ser considerada como un mecanismo de regulación.

La falta de nutrientes es capaz de producir señales que desatan la MCR en diferentes organismos y tejidos. Según el tipo celular y situación, el mecanismo de muerte puede ser apoptótica y/o autofágica y/o necrótica. Nos interesa especialmente analizar el ejemplo de la deprivación de glucosa que activa el mecanismo de pérdida de la viabilidad celular que es similar en células de eucariotas inferiores como la levadura Saccharomyces cerevisiae y en células normales o tumorales de mamíferos (Ferretti et al., 2012b). Tanto en una célula de levadura como en una célula tumoral humana-que son muy diferentes en otros aspectos-el metabolismo energético se caracteriza por fermentar a la glucosa a alta velocidad. En ambos tipos de células la falta de glucosa induce de manera similar muerte apoptótica: esta apoptosis es disparada durante tal estrés energético mediante la activación de proteínas quinasas de señalización que responden a los niveles de adenosin fosfatos y conlleva un aumento de especies reactivas del oxígeno (ROS) producidas por las mitocondrias (Leadsham et al., 2010; Ferretti et al., 2012a).

Atendiendo a las características del metabolismo de la glucosa en estos tipos celulares, la falta de este sustrato produce, en principio, cambios en el citosol de las células, donde ocurre la glucólisis. Sin embargo, la diferente disponibilidad de glucosa no impacta sólo allí, sino que hay «señales»—usando términos de Green, Galluzzi y Kroemer (2014)—en la mitocondria que hacen que esta organela termine dirigiendo la muerte apoptótica. Ya sea por alteraciones tempranas en vías de señalización mitocondrial (e.g. adenosin monofosfato cíclico, ROS, etc.) o por alteraciones específicas de la maquinaria de la apoptosis mitocondrial (Leadsham et al., 2010; Ferretti et al., 2012a).

Vemos que una «señal» metabólica pura/única como la falta de glucosa, es traducida por proteínas quinasas de señalización («sensoras») tras la modificación de los niveles de adenosin fosfatos, y que, una vez activadas, estas proteínas sensoras modifican tanto a otros intermediarios como a proteínas directamente involucradas en promover la apoptosis en las células. Para las células de levadura, los primeros eucariotas, esto constituye una respuesta a un medio adverso. 
Teniendo en cuenta esto, podemos establecer la relación entre la MCR y los procesos de regulación de un organismo. En el caso de la levadura Saccharomyces cerevisiae, nos encontramos ante un organismo eucariota unicelular que, cuando se agotan los nutrientes del medio, entra en lo que se denomina «fase estacionaria», un estado en el que cesa de reproducirse y tienen lugar una serie de cambios en su metabolismo. Se ha demostrado que en Saccharomyces cerevisiae en estas condiciones se produce el aumento de la producción de especies reactivas del oxígeno y se induce apoptosis (Favre et al., 2008). Para las levaduras, en este estado de estrés nutricional es clave la activación de la proteína quinasa, PKA, que es la «sensora» responsable de poner en marcha el proceso de apoptosis (Leadsham et al., 2010). En otras palabras: la muerte apoptótica es aquí un mecanismo de regulación, ya que puede ser reconocido, por un lado, como un proceso de control de la proliferación celular y, por otro, como una respuesta a una serie de daños internos o externos de este organismo.

Podemos considerar también otro ejemplo, un conjunto de células normales en cultivo-extraídas de un órgano-que se constituyen como una monocapa que reproduce en alguna medida las características epiteliales del propio órgano o tejido multicelular. Estas células extraídas del órgano, al cultivarse en ausencia de glucosa, conservan evolutivamente las mismas vías involucradas en las levaduras en respuesta a la falta de glucosa (Ferretti et al., 2012a). Es decir, los mecanismos de control que se ejercen ante determinado estrés hacen posible que células, en principio muy distintas como lo son una célula de levadura, una célula de un órgano normal o una tumoral humana-activen del mismo modo el proceso de muerte.

Como dijimos, ante la falta de glucosa, en los tejidos mamíferos (normales o tumorales), se activan alguna/s proteínas quinasas que tienen como blancos enzimas/proteínas que cambian su actividad al ser reguladas por éstas. Uno de los fenómenos iniciales en esta vía de regulación es el cambio en los niveles (relativos) de adenosín fosfatos, lo mismo que sucedía en las levaduras. En efecto, el estrés energético provoca rápidamente el aumento de adenosin monofosfato cíclico que activa a la proteína quinasa PKA y también provoca el aumento de adenosin monofosfato que activa la proteína quinasa AMPK (Ferretti et al., 2012a; 2016). La primera con funciones bastante diversas (Tasken y Aandahl, 2004), la segunda es un tanto más específica de la regulación del metabolismo energético, ya que promueve la oxidación de glucosa y de ácidos grasos e inhibe procesos que consumen energía y contrarrestan la crisis energética (Hardie et al., 2012).

Estas son vías de señalización que están involucradas en el proceso de muerte y que, al igual que otras cascadas, en biología celular son conocidas como «vías de transducción de señales» (VTS). Las VTS, en tanto: 1) Involucran subsistemas especializados, es decir que no son directamente parte del control de las funciones básicas o constitutivas. 2) Conducen a un cambio en el régimen constitutivo (Bich et al., 2016), deben ser consideradas como parte constitutiva del sistema de regulación celular.

Pero, además, hay que tener en cuenta que en el proceso desatado por la crisis energética se activan, por los mismos mensajeros secundarios, otros subsistemas de regulación que producen cambios en las maquinarias de regulación la MCR y de la división celular. Tanto en las células de levadura como en las de tejidos mamíferos sometidos a falta de glucosa, con la activación de la vía adenosin monofosfato cíclico-PKA se producen modificaciones en proteínas claves de la respiración celular que llevan a la producción mitocondrial de especies reactivas del oxígeno que promueven el proceso de apoptosis (liberación de citocromo 
C mitocondrial, activación de caspasas, condensación cromatínica) (Ferretti et al., 2012a). En el caso de las células tumorales, que poseen una velocidad de división elevada, la activación de AMPK no sólo induce la MCR por apoptosis, sino que detiene el ciclo celular y las células enlentecen su división (Ferretti et al., 2016). En ambas respuestas, vemos la capacidad del organismo de producir un desplazamiento que va desde el sistema constitutivo al establecimiento de subsistemas especializados en el que están involucradas otras vías de señalización, diferentes a las primeras. (Figura 1).

\section{falta de glucosa}

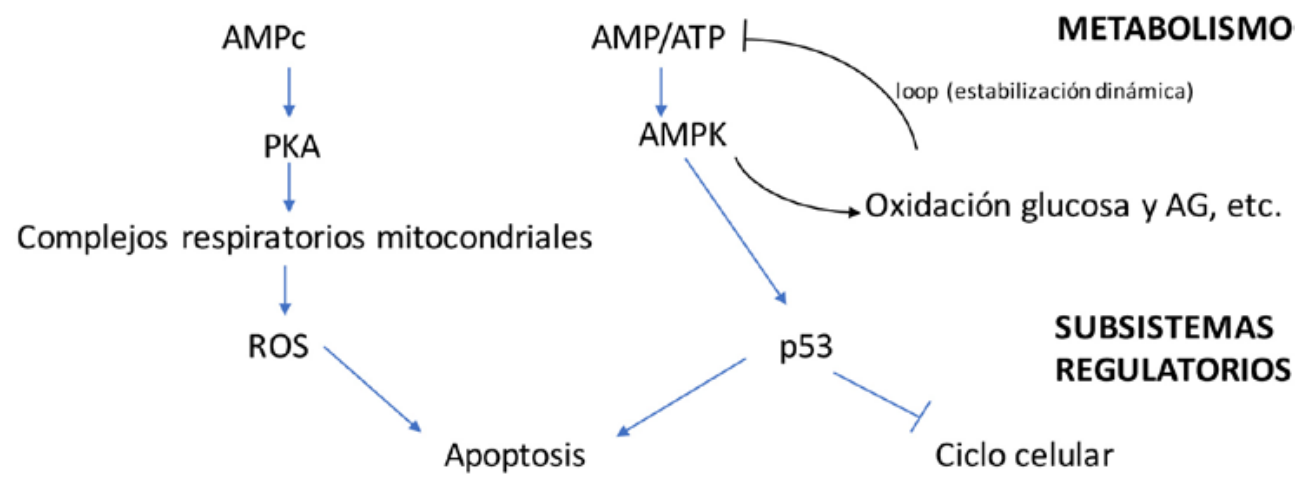

Figura 1

Esquema de los subsistemas regulatorios que conforman el proceso de señalización que conduce a la muerte celular en células eucariotas sometidas a falta de glucosa. Las líneas que terminan en punta de flecha indican activación y las que terminan en líneas indican inhibición. Las líneas de color negro indican procesos que pertenecen al metabolismo celular, y las de color azul procesos de regulación. La carencia de glucosa (cambio metabólico o perturbación original) produce aumentos de adenosín monofosfato cíclico (AMPc) y de adenosín monofosfato (AMP) - aumenta su relación respecto a ATP. PKA, proteína quinasa A; AMPK proteína quinasa activada por AMP; ROS, especies reactivas del oxígeno; AG, ácidos grasos.

En estos casos de MCR, los elementos constitutivos del metabolismo se entrelazan con susbsistemas específicos que regulan el destino celular permitiendo alternativas celulares frente a perturbaciones. Consecuentemente, interpretamos que la activación apoptótica de las células constitutivas de un organismo multicelular instaura una contribución al cierre organizacional. Es decir, consideramos que la MCR supone una contribución al auto-mantenimiento organizacional, pero no porque contribuya al mantenimiento de la estabilidad dinámica del sistema (de hecho, a través de la MCR el organismo pasa a tener una estructura diferente) sino porque es un mecanismo de regulación biológica, es decir un mecanismo de control del desarrollo de las relaciones funcionales intercelulares. La $\mathrm{MCR}$, en tanto regulación biológica, supone una forma de garantizar el mantenimiento de un cierre organizacional de segundo orden que preserva el cierre organizacional de primer orden que constituye el cierre de constricciones constitutivo de un organismo multicelular. 


\section{IV.2. Caso 2: La muerte CElular COMO REgulación PROGRAMAda}

Además de los ejemplos de este tipo, en los que la MCR se activa por un estímulo externo a la organización de la célula, hay otros casos en los que la MCR no tiene un origen exógeno. En estos casos la MCR se activa de forma «intrínseca» cuando una célula recibe una señal para destruirse a sí misma a partir de uno de sus propios genes o proteínas. A estos casos de MCR se los considera «muerte celular programada» (MCP).

La MCP es el fenómeno en el que las células mueren «a tiempo», es decir, siguen una programación interna que las lleva a morir en un momento específico. Durante el desarrollo de una cría de ave, por ejemplo, la morfología del ala se produce, entre otras cosas, como resultado de la muerte de grandes grupos de células. Si estos grupos de células no dejasen de existir en el momento adecuado no sería posible el desarrollo ontogenético. Del mismo modo, los tejidos de los individuos adultos no pueden permitirse una proliferación desmedida de células, por lo que un programa interno que lleve a la eliminación de las mismas bajo ciertas circunstancias supone una garantía para el auto-mantenimiento biológico. Hay, tal y como supo ver Saunders, un «reloj genético» que determina cuándo las células morirán. El momento de la muerte de una célula es cuando se activa el programa específico que determina la forma que tomará el suicidio celular.

Así, MCP es una forma fisiológica normal de MC que desempeña un papel clave tanto en el mantenimiento de los tejidos adultos como en el desarrollo embrionario. La forma paradigmática de MCP es la apoptosis, pero no es la única. En los adultos, la MCP es responsable de equilibrar la proliferación celular y mantener un número constante de células en los tejidos que experimentan una renovación celular. Por ejemplo, aproximadamente $5 \times 10^{11}$ células sanguíneas son eliminadas por MCP diariamente en humanos, equilibrando su producción continua en la médula ósea (Cooper 2000). Además, la MCP proporciona un mecanismo de defensa por el cual las células dañadas y potencialmente peligrosas pueden ser eliminadas por el bien del organismo en su conjunto. Las células infectadas por virus sufren con frecuencia una MCP, lo que impide la producción de nuevas partículas de virus y limita la propagación del virus a través del organismo huésped. Otros tipos de perturbaciones, como el daño al ADN, también inducen la MCP. En el caso del daño del ADN, la MCP puede eliminar las células portadoras de mutaciones potencialmente dañinas, incluidas aquellas que podrían conducir al desarrollo de cáncer.

La MCP juega un papel clave durante el desarrollo al eliminar las células no deseadas de una variedad de tejidos. Es responsable, por ejemplo, de descartar tejidos larvales durante la metamorfosis de anfibios e insectos, así como del desecho del tejido entre los dedos de las manos y de los pies. También ocurre durante el desarrollo del sistema nervioso de los mamíferos que hay producción neuronal en exceso y son eliminadas, por MCP, hasta el 50\% de las mismas. Las sobrevivientes son seleccionados por haber hecho las conexiones correctas con sus células diana, las cuales secretan factores de crecimiento que señalan la supervivencia celular al bloquear el programa de muerte celular neuronal. La supervivencia de muchos otros tipos de células en los animales también depende de factores de crecimiento o del contacto con células vecinas o con la matriz extracelular, por lo que se cree que la MCP desempeña un papel importante en la regulación de las asociaciones entre las células de los tejidos.

La apoptosis es la MCP más frecuente y está mediada por la actividad integrada de una serie de vías de señalización, algunas inducen la MC y otras promueven la supervivencia celular. El componente central en esta regulación son las proteínas de la familia $\mathrm{Bcl}-2$ que ac- 
túan como vía de señalización intrínseca. Esta vía se inicia, por ejemplo, cuando hay daños en el ADN y no puedan ser reparados. Este suceso provoca la liberación al citosol de citocromo c, una proteína que normalmente existe en el espacio entre las membranas de las mitocondrias. La liberación de citocromo $\mathrm{c}$ inicia la «cascada de caspasas». Esta liberación ocurre cuando las proteínas pro-apoptóticas de la familia Bcl-2 (Bax, Bak) se unen para formar un canal en la membrana mitocondrial externa. En condiciones normales, existe un equilibrio entre las proteínas antiapoptóticas y las pro-apoptóticas: las proteínas antiapoptóticas (como $\mathrm{Bcl}-2$ y Bcl-xL) se unen a las pro-apoptóticas, secuestrándolas e impidiendo que se formen los canales. Pero cuando el ADN está dañado se sintetizan otras proteínas pro-apoptóticas de la familia $\mathrm{Bcl}-2$ denominadas $\mathrm{BH} 3$-only que inhiben a las antiapoptóticas permitiendo a las pro-apoptóticas formar complejos en la membrana mitocondrial. Cuando el citocromo c es liberado al citosol, se une al factor 1 de activación de la proteasa apoptótica (Apaf-1) que así oligomeriza y forma el apoptosoma, el cual activa la caspasa 9 (la caspasa iniciadora de la cascada), que activa el efector caspasa 3, que descompone las proteínas intracelulares (Fuchs y Steller, 2015).

Consecuentemente, podemos ver que la MCP, sin inducción exógena, es también un mecanismo de regulación biológica. De acuerdo al trabajo de Bich et al. (2016), nos encontramos con que para que un proceso se considere regulatorio deben cumplirse las siguientes condiciones:

(1) Los mecanismos/subsistemas reguladores $\mathrm{R}$ son sintetizados endógenamente: es decir, son producidos por el régimen constitutivo $\mathrm{C}$ del sistema vivo;

(2) Para ser regulatorio, $\mathrm{R}$ debe estar desacoplado dinámicamente de $\mathrm{C}$, al cual regula. Esto significa que $\mathrm{R}$, incluso si es un producto de $\mathrm{C}$, opera a una escala dinámica diferente y con requisitos estequiométricos diferentes a los de $\mathrm{C}$;

(3) La activación de $\mathrm{R}$ se desencadena por cambios/perturbaciones específicos en las condiciones internas o externas, más que por un cambio en la concentración de los componentes en R;

(4) El papel funcional de R es llevar a C (reversible o irreversiblemente) a instanciar un régimen constitutivo/metabólico distinto, disponible para el sistema, dependiendo de las variaciones en sus condiciones internas o externas que desencadenan la activación de R;

(5) Los nuevos regímenes metabólicos/constituyentes que presenta $\mathrm{R}$ son capaces de hacer frente a las nuevas condiciones, ampliando la gama de perturbaciones o estímulos a los que el sistema puede responder de forma rápida y eficaz, así como de enriquecer la esfera de comportamientos dinámicos funcionales disponibles. (Bich et al., 2016, p. 17)

En el ejemplo de la sección anterior-la MCR desencadenada por factores extrínsecos-se cumplen indudablemente estas condiciones. El mecanismo de MC (1) está producido internamente, (2) está dinámicamente desacoplado del sistema que lo produce, ${ }^{7}$ (3) está ac-

La necesidad de introducir la idea de desacoplamiento dinámico deriva del hecho de que la regulación implica una fuerte asimetría y una relación jerárquica entre los diferentes módulos o subsistemas de un sistema. En los sistemas artificiales, la regulación se entiende implícitamente como un cambio en los parámetros del sistema operado por diseñadores humanos, cuyos protocolos de construcción y objetivos tecnológicamente sesgados introducen escalas de comportamiento temporal/espacial completamente di- 
tivado por perturbaciones en las condiciones externas, (4) lleva al organismo multicelular a un régimen metabólico distinto al cambiar su misma constitución celular y es, por ello, (5) capaz de afrontar la perturbación del entorno.

En el ejemplo de esta sección, en el que la MCR es de origen intrínseco, esto puede resultar más dudoso por no satisfacerse la condición 3, al no haber cambios en las condiciones internas o externas. Podría pensarse, por tanto, que estos mecanismos de MC no son realmente una respuesta a cambio alguno, sino que se tratan de procesos derivados de una programación. No obstante, en realidad la apoptosis intrínseca se inicia también ante la presencia de toda una variedad de perturbaciones que ocurren en el ámbito interno de la célula: un retraimiento en el factor de crecimiento, un daño en el ADN, la presencia de estrés del retículo endoplasmático o mitocondrial, o la detección de alteraciones microtubulares o defectos mitóticos (Czabotar et al., 2014).

La MCR, independientemente de que sea desencadenada de forma extrínseca o intrínseca, merece realmente la calificación de «regulatoria», además de la de «regulada». La MCR es el resultado de la activación de un conjunto de interacciones entre actores bioquímicos definidos que involucra la modulación de mecanismos, que conducen a distintos procesos (e.g. apoptosis, autofagia, necrosis). Estos mecanismos son equiparables a los subsistemas de regulación biológica propuestos por Bich et al. (2016). Además, los procesos de MCR pueden interpretarse como funciones de la célula ya que cumplen con las tres condiciones necesarias mencionadas en la sección III, a saber, $(\mathrm{C} 1)$ la célula, con su propia muerte debida a la MCR, contribuye al mantenimiento de la organización del organismo multicelular, (C2) la célula con sus propiedades, incluída la capacidad de MCR, es producida y mantenida por constricciones ejercidas por esta organización, y, finalmente, (C3) el organismo en el cual se da la MCR de las células es un multicelular que presenta una organización que realiza cierre organizacional.

\section{$V$. Conclusiones. Morir para vivir: la MCR como regulación}

Hay algo que es evidente y es que no se puede estar vivo y muerto al mismo tiempo, sin embargo, esta condición no implica que vida y muerte sean conceptos netamente contrarios ni fenómenos esencialmente incompatibles. Si bien la vida ha sido definida por algunos teóricos como el conjunto de funciones que resiste a la muerte (Bichat, 1994; Hershenov, 2003), hemos visto aquí que la vida no puede reducirse a la sola resistencia a la muerte, y que hay al menos un tipo de muerte, la MCR, que no puede ser interpretada como el resultado del colapso de las funciones de un organismo.

Para comprender en qué sentido puede fundamentarse la noción de «regulación» que asumen los biólogos celulares cuándo hablan de MCR, tomamos como punto de partida una caracterización de las organizaciones biológicas que nos permite incluir conceptualmente la MCR como un proceso funcional de cierto tipo de organismos. Vimos que todo

ferentes. En los sistemas naturales, sin embargo, no se puede identificar un proceso de regulación a menos que el sistema genere en sí mismo una clara diferenciación dinámica, que por supuesto debe satisfacer los requisitos funcionales y estequiométricos globales implicados (Bich et al., 2016, p. 18). Se puede encontrar un análisis detallado en Ruiz-Mirazo y Moreno (2004) y Moreno y Mossio (2015). 
sistema viviente posee un cierre organizacional que le es propio, que lo define e identifica, que es activo en su relación con el medio (Mossio y Moreno, 2010). Consecuentemente, la organización de un ser viviente está sujeta a una identidad susceptible a cambios de estado que determinan el tipo concreto de intercambio de materia y energía con el ambiente que permite el auto-mantenimiento biológico. En el caso de los organismos multicelulares, no es posible conservar la identidad del organismo en su conjunto sino se da, por un lado, un conjunto de procesos interactivos entre el organismo y el entorno que contribuyan al mantenimiento de la organización constitutiva del sistema y, por otro lado, un mecanismo regulatorio que guíe el desarrollo de las relaciones funcionales entre las partes unicelulares autónomas el conjunto de la organización integrada autorreproducible y automantenible.

En este trabajo, hemos analizado diferentes ejemplos de MCR y hemos mostrado cómo, ante una situación crítica-como la falta de glucosa (estrés energético)—y con consecuencias directas sobre el metabolismo-el régimen constitutivo-, una célula de un organismo multicelular puede desencadenar una serie de señales metabólicas que activan vías de regulación-subsistemas regulatorios-diferentes a las del régimen constitutivo. En consecuencia, concluimos que la MCR es, más que el resultado de una regulación, tal y como parece entenderse frecuentemente, un proceso regulatorio que produce cambios a nivel organizacional en el sistema que, como hemos visto, pueden incluir la detención del ciclo celular y la interrupción de la actividad proliferativa, o una serie de modificaciones moleculares que devengan en la muerte apoptótica de la célula, conformando así un nuevo cierre organizacional de segundo orden (Mossio y Moreno, 2010).

En resumen, la MCR de una célula se constituye como un proceso regulatorio que posee cuatro características:

a) se activa cuando existen cambios (metabólicos) que son reconocidos como críticos,

b) modifica el régimen constitutivo de la célula, (e.g. disminuye y restringe el uso de su energía),

c) acaba con la pérdida de la identidad celular, esto es, su capacidad de diferenciarse-y comunicarse-con el medio y deja por tanto de ser parte constitutiva de un organismo multicelular; y

d) esta pérdida de la identidad de la célula permite una nueva organización y la integridad funcional del conjunto del organismo multicelular.

La MCR es, consecuentemente, un fenómeno funcional que, como proceso biológico diferenciado de regulación, contribuye a la organización del sistema viviente, favorece a su auto-mantenimiento y preserva su identidad. Por lo tanto, podemos concluir que, contra la concepción popular y las asunciones de gran parte de la ciencia biológica, hay al menos ciertos tipos de muerte, como la MCR, que no son solo ausencia de vida, sino también una condición de posibilidad de esta.

\section{REFERENCIAS}

Arnellos, A., Moreno, A. \& Ruiz-Mirazo, K. (2014). Organizational requirements for multicelular autonomy: insights from a comparative case study. Biology \& Philosophy, 29, 851-884.

Arnellos, A. \& Moreno, A. (2015). Multicellular agency: an organizational view. Biology \& Philosophy, 30, 333-357. 
Artal-Sanz, M., Samara, C., Syntichaki, P., y Tavernarakis, N. (2006). Lysosomal biogenesis and function is critical for necrotic cell death in Caenorhabditis elegans. Journal of Cell Biology, 173(2), 231-239.

Bich, L., Mossio, M., Ruiz-Mirazo, K. \& Moreno, A. (2016). Biological regulation: controlling the system from within. Biology \& Philosophy, 31(2), 237-265.

Bichat, X. (1994). Recherches physiologiques sur la vie et la mort. Paris: GF-Flammarion.

Büttner, S., Eisenberg, T., Herker, E., Carmona-Gutierrez, D., Kroemer, G. \& Madeo, F. (2006). Why yeast cells can undergo apoptosis: death in times of peace, love, and war. Journal of Cell Biology, 175, 521-525.

Campero, M. B. \& Favre, C. (2012). Res computans: The living subject from yeast to human. Axiomathes, 22, 457-468.

Campero, M. B. (2017). Un individuo-sujeto. El yo como una unidad compleja. Revista de Filosofía Universidad Complutense de Madrid, 42, 1-18.

Carmona-Gutierrez, D., Eisenberg, T., Büttner, S., Meisinger, C., Kroemer, G. \& Madeo, F. (2010). Apoptosis in yeast: triggers, pathways, subroutines. Cell Death and Differentiation, 17, 763.

Chautan, M., Chazal, G., Cecconi, F., Gruss, P., y Golstein, P. (1999). Interdigital cell death can occur through a necrotic and caspase-independent pathway. Current Biology, 9(17), 967-S1.

Clarke, P. \& Clarke S. (1996). Nineteenth century research on naturally occurring cell death and related phenomena. Anatomy and Embryology, 193, 81-99.

Cooper, G. M., Hausman, R. E. \& Hausman, R. E. (2000). The cell: a molecular approach (Vol. 10). Washington, DC: ASM press.

Czabotar, P. E., Lessene, G., Strasser, A. \& Adams, J. M. (2014). Control of apoptosis by the BCL-2 protein family: implications for physiology and therapy. Nature reviews Molecular cell biology, 15(1), 49.-63.

Durand P. M. \& Ramsey G. (2019). The Nature of Programmed Cell Death. Biological Theory, 14, 30-41.

Engelberg-Kulka, H., Amitai, S., Kolodkin-Gal, I. \& Hazan, R. (2006). Bacterial programmed cell death and multicellular behavior in bacteria. PLoS genetics, 2(10), e135.

Favre, C., Aguilar, P. \& Carrillo, M. (2008). Oxidative stress and chronological aging in glycogen-phosphorylase-deleted yeast. Free Radical Biology and Medicine, 45, 1446-1456.

Feldman, F. (1989). On dying as a process. Philosophy and Phenomenological Research, 50, 375-390.

Feldman, F. (1992). The enigma of death. Philosophia, 21, 163-181.

Feldman, F. (1994). Confrontations with the reaper: A philosophical study of the nature and value of death. New York: Oxford University Press.

Ferretti, A. C., Mattaloni, S. M., Ochoa, J. E., Larocca, M. C. \& Favre, C. (2012a). Protein kinase A signals apoptotic activation in glucose-deprived hepatocytes: participation of reactive oxygen species. Apoptosis, $17(5), 475-491$.

Ferretti, A. C., Larocca, M. \& Favre, C. (2012b). Nutritional stress in eukaryotic cells: oxidative species and regulation of survival in time of scarceness. Molecular Genetics and Metabolism, 105, 186-192.

Ferretti, A. C., Tonucci, F. M., Hidalgo, F., Almada, E., Larocca, M. C. \& Favre, C. (2016). AMPK and PKA interaction in the regulation of survival of liver cancer cells subjected to glucose starvation. Oncotarget, 7(14), 17815.

Fuchs, Y. \& Steller, H. (2011). Programmed cell death in animal development and disease. Cell, 147(4), $742-$ 758.

Fuchs, Y. \& Steller, H. (2015). Live to die another way: modes of programmed cell death and the signals emanating from dying cells. Nature Reviews Molecular Cell Biology, 16: 329.

Galluzzi, L., Bravo-San Pedro, J. M., Kepp, O. \& Kroemer, G. (2016). Regulated cell death and adaptive stress responses. Cellular and Molecular Life Sciences, 73(11-12), 2405-2410.

Galluzzi, L., Vitale, I., Aaronson, S. A., Abrams, J. M., Adam, D., Agostinis, P. \& Annicchiarico-Petruzzelli, M. (2018). Molecular mechanisms of cell death: recommendations of the Nomenclature Committee on Cell Death 2018. Cell Death \& Differentiation, 25(3), 486.

Gilmore, C. (2003) When do things die? In B. Bradley, J. Johansson \& F. Feldman, (Eds.). The Oxford handbook of philosophy and death: Oxford University Press. 
Golstein, P. \& Kroemer, G. (2007). Cell death by necrosis: towards a molecular definition. Trends in Biochemical Sciences, 32, 37-43.

Green, D. \& Llambi, F. (2015). Cell death signaling. Cold Spring Harbor Perspectives in Biology, 7, a006080.

Green, D., Galluzzi, L. \& Kroemer, G. (2014). Metabolic control of cell death. Science, 345, 1250256.

Grether, M. E., Abrams, J. M., Agapite, J., White, K. \& Steller, H. (1995). The head involution defective gene of Drosophila melanogaster functions in programmed cell death. Genes \& Development, 9(14), 1694-1708.

Hardie, D., Grahame, F. \& Hawley, S. (2012). AMPK: a nutrient and energy sensor that maintains energy homeostasis. Nature Reviews Molecular Cell Biology, 13, 251-262.

Herker, E., Jungwirth, H., Lehmann, K. A., Maldener, C., Fröhlich, K. U., Wissing, S. \& Madeo, F. (2004). Chronological aging leads to apoptosis in yeast. Journal of Cell Biology, 164(4), 501-507.

Hershenov, D. (2003). The problematic role of 'irreversibility' in the definition of death. Bioethics, 17, 89-100.

Hotchkiss, R. S., Strasser, A., McDunn, J. E. \& Swanson, P. E. (2009). Cell death. New England Journal of Medicine, 361(16), 1570-1583.

Ioannidis, S. \& Psillos, S. (2017). In defense of methodological mechanism: The case of apoptosis. Axiomathes, 27: 601-619.

Janssen, E. M., Droin, N. M., Lemmens, E. E., Pinkoski, M. J., Bensinger, S. J., Ehst, B. D. \& Schoenberger, S. P. (2005). CD4+ T-cell help controls CD8+ T-cell memory via TRAIL-mediated activation-induced cell death. Nature, 434(7029), 88.

Jonas, H. (2001) The phenomenon of life: toward a philosophical biology. Evanston: Northwestern University Press.

Juarrero, A. (2015). What does the closure of context-sensitive constraints mean for determinism, autonomy, self-determination, and agency? 2015. Progress in Biophysics and Molecular Biology, 119, 510-521.

Kaiser, D. (2001). Building a multicellular organism. Annual Review of Genetics, 35, 103-123.

Kelemen, D. (2004). Are children «intuitive theists»? Reasoning about purpose and design in nature. Psychological Science, 12, 295-301.

Kerr, J. F. R., Wyllie, A. H. \& Currie, A. R. (1972). Apoptosis: a basic biological phenomenon with wide-ranging implications in tissue kinetics. British Journal of Cancer, 26, 239-257.

Kroemer, G., El-Deiry, W. S., Golstein, P., Peter, M. E., Vaux, D., Vandenabeele, P., ... \& Piacentini, M. (2005). Classification of cell death: recommendations of the Nomenclature Committee on Cell Death. Cell Death and Differentiation, 12(12), 1463-1467.

Leadsham, J. \& Campbell W. (2010). cAMP/PKA signaling balances respiratory activity with mitochondria dependent apoptosis via transcriptional regulation. BMC Cell Biology, 11, 92.

Lockshin, R. A. (2016). Programmed cell death 50 (and beyond). Cell Death and Differentiation, 23, 10-17.

Lockshin, R. A. \& Williams, C. M. (1964). Programmed cell death-II. Endocrine potentiation of the breakdown of the intersegmental muscles of silkmoths. Journal of Insect Physiology, 10, 643-649.

Maiuri, M. C., Zalckvar, E., Kimchi, A. \& Kroemer, G. (2007). Self-eating and self-killing: crosstalk between autophagy and apoptosis. Nature Reviews Molecular Cell Biology, 8(9), 741.

Maturana, H. \& Varela, F. (1980). Autopoiesis and cognition. The realization of the living. Dordrecht: Reidel.

Montévil, M. \& Mossio, M. (2015). Biological organisation as closure of constraints. Journal of Theoretical Biology, 372, 179-191.

Moreno, A. \& Mossio, M. (2015). Biological autonomy. A philosophical and theoretical enquiry. Springer.

Mossio, M., Saborido, C. \& Moreno, A. (2009). An organizational account of biological functions. British Journal of Philosophy of Science, 60, 813-841.

Mossio, M. \& Moreno, A. (2010). Organisational closure in biological organisms. History and Philosophy of the Life Sciences, 269-288.

Mossio, M., Bich, L. \& Moreno, A. (2013). Emergence, closure and inter-level causation in biological systems. Erkenntnis, 78, 153-178.

Nishina, T., Komazawa-Sakon, S., Yanaka, S., Piao, X., Zheng, D. M., Piao, J. H., ... \& Doi, T. (2012). Interleukin-11 links oxidative stress and compensatory proliferation. Science Signaling, 5(207), ra5-ra5. 
Oró, J. (2002). Historical understanding of life's beginnings. In J. W. Schopf (Ed.). Lifes origin (pp. 7-45). Berkeley: University of California Press.

Pérez-Garijo, A., Fuchs, Y. \& Steller, H. (2013). Apoptotic cells can induce non-autonomous apoptosis through the TNF pathway. Elife, 2, e01004.

Persson, I. (1995). What is Mysterious about Death? The Southern Journal of Philosophy, 33, 499-508.

Rice, Kelly C. \& Kenneth W. Bayles (2003). Death's toolbox: examining the molecular components of bacterial programmed cell death. Molecular Microbiology, 50, 729-738.

Ruiz-Mirazo, K. \& Moreno, A. (2004). Basic autonomy as a fundamental step in the synthesis of life. Artificial Life, 10, 235-259.

Ruiz-Mirazo, K., Peretó, J. \& Moreno, A. (2004). A universal definition of life: autonomy and open-ended evolution. Origins of Life and Evolution of the Biosphere, 34, 323-346.

Ruiz-Mirazo, K., Peretó, J. \& Moreno, A. (2010). Defining life or bringing Biology to life. Origins of Life and Evolution of Biosphere, 40, 203-213.

Saunders, J. (1966). Death in embryonic systems. Science, 154, 604-612.

Saborido, C., Mossio, M. \& Moreno, A. (2011). Biological organization and cross-generation functions. British Journal of Philosophy of Science, 62, 583-606.

Saborido, C. (2014a) New directions in the Philosophy of Biology: a New Taxonomy of Functions. In C. Galavotti, S. Hartmann, M. Weber, W. Gonzalez, D. Dieks \& T. Uebel (Eds.) New directions in the philosophy of science (pp. 235-251). Springer.

Saborido, C. (2014b). Diseño, Evolución y Organización. La Teleología en la Filosofía de las Ciencias Biológicas. Acta Scientiae, 16, 284-309.

Tasken, K. \& Aandahl, E. (2004). Localized effects of cAMP mediated by distinct routes of protein kinase A. Physiological Reviews, 84, 137-167.

Umerez, J. (2001). Howard Pattee's theoretical biology a radical epistemological stance to approach life, evolution and complexity. Biosystems, 60, 159-177.

Varela, F. (1979). Principles of Biological Autonomy. NewYork: Nort-Holland.

María Belén Campero es investigadora del Centro de Investigaciones Filosóficas (CIF). Dra. en Filosofía por la Universidad Nacional de Rosario. Recibió varias becas para formación doctoral y postdoctoral. Realizó estancias de investigación en Paris 8, junto al Dr. Patrice Vermeren y en UNED al Dr. Cristian Saborido. Autora de varias publicaciones científicas en revistas internacionales de investigación.

Address: Centro de Investigaciones Filosóficas, Buenos Aires, Argentina. Miñones 2073. C1428ATE Buenos Aires. Argentina. E-mail: bcampero@gmail.com

Cristián Favre es Bioquímico y Doctor en Ciencias Biológicas. Es docente de Fisiología en la Universidad Nacional de Rosario e investigador del CONICET. Se ha especializado en metabolismo y muerte celular y actualmente investiga con su grupo la señalización en células tumorales sometidas a estrés energético. También participa en proyectos de filosofía de la biología analizando conceptos como el de supervivencia celular en relación a las ideas de sujeto u organización, entre otras.

Address: Instituto de Fisiología Experimental, CONICET, UNR, Rosario, Argentina. Suipacha 570. S2002LRL Rosario. Argentina. E-mail: favre@ifise-conicet.gov.ar

Cristian Saborido es profesor del departamento de Lógica, Historia y Filosofía de la Ciencia de la UNED. Doctor en Filosofía por la Universidad del País Vasco / Euskal Herriko Unibertsitatea. Especializado en Filosofía de la Ciencia, Filosofía de la Biología, Filosofía de la Medicina y Bioética. Autor de varias publicaciones en estas áreas en diversas compilaciones y revistas internacionales de investigación.

Address: Departamento de Lógica, Historia y Filosofía de la Ciencia, UNED, Madrid, España. Paseo Senda del Rey, 7. 28040 Madrid. España. E-mail: cristian.saborido@fsof.uned.es 